\title{
Cannabis Use Patterns and Their Association with DSM-IV Cannabis Dependence and Gender
}

\author{
R. Noack ${ }^{a, b}$ M. Höfler ${ }^{b} \quad$ U. Lueken ${ }^{b}$ \\ a University Hospital for Psychotherapy and Psychosomatic Medicine and ${ }^{\mathrm{b}}$ Institute of Clinical Psychology and \\ Psychotherapy, Technische Universität Dresden, Dresden, Germany
}

Key Words

Cannabis $\cdot$ Gender $\cdot$ Patterns of use $\cdot$ Dependence $\cdot$ DSM-IV

\begin{abstract}
Aims: To investigate the gender differences in the patterns of cannabis use (CU), namely frequency, times of day, social context and methods and in their association with DSM-IV cannabis dependence. Methods: A sample of 3,904 students from German universities was recruited via an internet survey. Logistic regressions and associated areas under the ROC curve (AUC) were calculated among current cannabis users (at least once a month, $\mathrm{n}=843$ ). Results: CU using a water pipe was more often reported by males (50 vs. 34.6\%). Usual CU 'before going to sleep at night' was more often reported by females (47.3 vs. $35.7 \%$ ). Most CU patterns showed a similar association with DSM-IV cannabis dependence in both genders. The association of CU 'with strangers' was stronger in females (AUC 0.68 vs. AUC 0.56). Slightly different multiple models were found (females AUC 0.86, males AUC 0.77). Conclusions: There are considerable gender differences in the CU patterns and, thus, in the way CU functions. In the association of CU patterns with cannabis dependence, the similarities are rather great. Examining the $\mathrm{CU}$ patterns might make a considerable contribution to the better detection of high-risk population segments for prevention and early intervention in both genders.

Copyright $\odot 2011$ S. Karger AG, Basel
\end{abstract}

\section{Introduction}

Cannabis continues to be the most prevalent illicit drug used in Germany and in most European countries as well as worldwide $[1,2]$. Cannabis use (CU) is associated with the development of physiological, social and legal problems [3]. Besides, there is also a high comorbidity with mood and anxiety disorders $[4,5]$. After an increase in the last two decades, the prevalence of CU in Germany has remained at a high level during the past years. There are approximately 600,000 individuals fulfilling the criteria for CU disorders, either as cannabis dependence or cannabis abuse [6], with a rising number of individuals seeking treatment in outpatient facilities [7].

The $\mathrm{CU}$ gender differences known so far are that $\mathrm{CU}$ is more prevalent in males than in females [6] and that men are more likely to meet the criteria for $\mathrm{CU}$ disorders $[8,9]$. In Germany, $0.6 \%$ males and $0.3 \%$ females meet the criteria for cannabis dependence, and $1.2 \%$ males and $0.3 \%$ females meet the criteria for cannabis abuse [6]. Furthermore, there are assumed gender differences in the $\mathrm{CU}$ functionality of females and males: male cannabis users more frequently report mood enhancement as their main motive for CU while females are more likely to use cannabis for coping with anxiety and depressive symptoms as well as with tension and stressors [10]. In line with this, a higher comorbidity of cannabis dependence with anxiety

\section{KARGER}

Fax +41613061234 E-Mail karger@karger.ch www.karger.com
(C) 2011 S. Karger AG, Basel

$1022-6877 / 11 / 0176-0321 \$ 38.00 / 0$

Accessible online at:

www.karger.com/ear
René Noack, Dipl.-Psych.

University Hospital for Psychotherapy and Psychosomatic Medicine

Technische Universität Dresden

Fetscherstrasse 74, DE-01307 Dresden (Germany)

Tel. +49 351458 5990, E-Mail noack@psychologie.tu-dresden.de 
and depressive symptoms has been reported for females [5, 11]. Although similar patterns concerning cannabis problems were reported by Grant et al. [12] for both genders, more frequent hazardous use was found in males whereas females more frequently reported withdrawal symptoms.

Less is known about the gender differences in reference to the CU patterns (e.g. frequency, times of day, method and social context), although some patterns of $\mathrm{CU}$ in previous analyses among the current sample appear to be closely related to cannabis dependence [13]. Therefore, the main aim of this study was (1) to detect gender differences in prevalence of CU patterns and, thus, in the functionality of $\mathrm{CU}$ in order to improve the etiological models concerning the development of cannabis dependence, and (2) to investigate the benefit of detecting patterns of $\mathrm{CU}$ in gender relation in the improvement of diagnosing cannabis dependence for the sake of prevention and early intervention approaches.

The 'frequency' of CU remains the best reviewed pattern of CU. In several studies, the 'frequency' of CU consistently remained strongly associated with the progression of CU to CU disorders [e.g. 8, 13, 14]. Combining this with dimensional, quantifiable criteria for the revision of the Diagnostic and Statistical Manual of Mental Disorders (DSM) has been proposed [15]. The 'amount of cannabis used' was a weaker predictor than the 'frequency' of CU [16], possibly due to the large variance of $\Delta^{9}$-tetrahydrocannabinol in street cannabis (between $<1$ and 17\%) [17]. Simon et al. [18] and Noack et al. [13] showed a strong association of other specific CU patterns with DSM-IV cannabis dependence beyond any gender differences which suggests the specific role of the CU patterns in the process of progression from CU to cannabis dependence. Nevertheless, less is known about the gender differences in the association of the CU patterns with cannabis dependence.

A strong association of more frequently $\mathrm{CU}$ 'upon rising' with cannabis dependence in the cannabis users at German outpatient facilities [18] and in cannabis-using German students [13] was found. Furthermore, an association of CU 'before going to sleep at night' with cannabis dependence could be found $[13,18]$. This may be in line with sleep problems presenting an important withdrawal symptom as mentioned by Budney et al. [19]. These CU patterns may increase the risk or the quick progression of the transition to cannabis dependence. However, in this context, gender differences have remained largely unknown.

Concerning the social context of CU, Hesse et al. [20] reported that attending social events such as music festivals often initiates the onset of CU. An even strong asso- ciation of smoking 'alone' with cannabis dependence was found in cannabis users coming to German outpatient facilities [18] as well as in German students [13]. There might be a connection of CU offside a social context in anticipation of coping with discomfort (e.g. stress, emotional pain) as reported by Beck et al. [21]. Hence, CU offside a social context may be an important factor in the onset of cannabis dependence. On the other hand, Beck et al. [21] reported that, over time, the social facilitation of CU was related to the persistence of cannabis dependence among college students. Little is known about the relationships between the social context of CU and cannabis dependence in females compared to males.

In contrast to other illegal substances (e.g. heroin), little is known about the role use methods play in the development of cannabis dependence. Besides the most common inhalation method of 'smoking joints', there exist other, more intense inhalation methods that allow for the consumption of more cannabis at a time mainly by 'smoking water pipe' also known as a 'bong' or, otherwise, by 'smoking a pail' as described by Bonnet et al. [22]. These excessive use methods are common in adolescents and young adults and are assumed to be related to the development of cannabis dependence [13, 18, 22]. In German students, CU by using a 'water pipe' or 'smoking a pail' is associated with the presence of DSM-IV cannabis dependence [13]. However, gender differences concerning CU by excessive use methods and the association with cannabis dependence still remain largely unknown.

\section{Methods}

Assessment

The data for this study were collected using an internet survey conducted in summer 2007. The development and the implementation of this survey are described in detail by Noack et al. [13]. It was carried out in accordance with the ethical guidelines of the American Psychological Association [23] commented for internet surveys by Keller and Lee [24]. The approval for this study was given by the ethic committee of the Medizinische Fakultät Carl Gustav Carus of the Technische Universität Dresden (EK 39022009). To yield a sample with a high rate of cannabis users, young adults were targeted. To ensure that the participants were adults (18 or older) and had an easy access to the internet, a source population of German university students were selected. Therefore, the 1,335 student councils at the German universities located on the internet were contacted by e-mail for posting information about the internet survey on their bulletin boards, electronic bulletin boards and internet homepages.

Regarding the present analyses, the following items were presented in the survey: the criteria of DSM-IV cannabis dependence during the last 12 months were collected based on Munich-Composite International Diagnostic Interview (M-CIDI) [25]. CU pat- 
Table 1. Demographics, DSM-IV cannabis dependence and other substances use among analysis sample: current cannabis-using students (at least once a month during the last 12 months)

\begin{tabular}{|c|c|c|c|}
\hline Characteristic & All $(n=843) \%$ & Female $(n=248) \%$ & Male $(\mathrm{n}=595) \%$ \\
\hline \multicolumn{4}{|l|}{ Gender $(\mathrm{n}=843)$} \\
\hline Male & 70.6 & & \\
\hline \multicolumn{4}{|l|}{ Age $(n=843)$} \\
\hline $18-20$ & 63.0 & 68.6 & 60.7 \\
\hline $21-24$ & 33.8 & 28.6 & 36.0 \\
\hline $25-29$ & 3.0 & 2.4 & 3.2 \\
\hline $30-59$ & 0.2 & 0.4 & 0.2 \\
\hline DSM-IV cannabis dependence $(\mathrm{n}=782)$ & 31.5 & 25.5 & 33.9 \\
\hline \multicolumn{4}{|c|}{ Number of DSM-IV cannabis dependence criteria $(n=664)$} \\
\hline 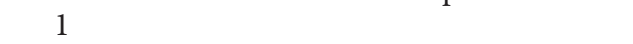 & 24.4 & 23.0 & 25.0 \\
\hline 2 & 18.4 & 19.0 & 18.1 \\
\hline$\geq 3$ & 30.0 & 25.5 & 31.9 \\
\hline \multicolumn{4}{|l|}{ DSM-IV cannabis dependence criteria } \\
\hline Tolerance $(\mathrm{n}=809)$ & 39.2 & 34.2 & 41.3 \\
\hline Withdrawal $(\mathrm{n}=808)$ & 14.9 & 14.3 & 15.1 \\
\hline Use because of withdrawal $(n=809)$ & 14.7 & 17.7 & 13.5 \\
\hline Loss of control $(\mathrm{n}=801)$ & 50.7 & 48.5 & 51.6 \\
\hline Desire to control use $(n=807)$ & 21.3 & 14.9 & 24.0 \\
\hline Excess time obtaining/recovering $(\mathrm{n}=805)$ & 28.5 & 25.9 & 29.5 \\
\hline Cutback of behavior repertoire $(n=809)$ & 14.3 & 10.0 & 16.2 \\
\hline Use despite health problem $(\mathrm{n}=757)$ & 22.6 & 22.4 & 22.7 \\
\hline \multicolumn{4}{|l|}{ Other substance use } \\
\hline \multicolumn{4}{|l|}{ 12-Month prevalence } \\
\hline Alcohol $(\mathrm{n}=833)$ & 98.1 & 98.8 & 97.8 \\
\hline Meth-/amphetamine $(\mathrm{n}=826)$ & 14.4 & 15.0 & 14.1 \\
\hline Ecstasy $(\mathrm{n}=819)$ & 9.9 & 10.2 & 9.7 \\
\hline Cocaine $(\mathrm{n}=824)$ & 11.9 & 11.8 & 11.9 \\
\hline $\operatorname{LSD}(\mathrm{n}=821)$ & 4.9 & 5.3 & 4.7 \\
\hline Heroin $(n=821)$ & 0.2 & 0.0 & 0.3 \\
\hline \multicolumn{4}{|l|}{ At least monthly } \\
\hline Alcohol $(\mathrm{n}=833)$ & 90.8 & 86.7 & 92.5 \\
\hline Meth-/amphetamine $(\mathrm{n}=826)$ & 2.3 & 3.7 & 1.7 \\
\hline Ecstasy $(\mathrm{n}=819)$ & 1.2 & 1.2 & 1.2 \\
\hline Cocaine $(\mathrm{n}=824)$ & 1.5 & 2.0 & 1.2 \\
\hline $\operatorname{LSD}(\mathrm{n}=821)$ & 0.2 & 0.4 & 0.2 \\
\hline Heroin $(\mathrm{n}=821)$ & 0.0 & 0.0 & 0.0 \\
\hline \multicolumn{4}{|l|}{ At least 3 days a week } \\
\hline Alcohol $(\mathrm{n}=833)$ & 25.2 & 19.0 & 27.9 \\
\hline
\end{tabular}

terns were asked for in four category groups: frequency, times of day, social context and method of CU with altogether 15 items. 'Frequency' of CU during the last 12 months was assessed using the M-CIDI [25]. All the other items concerning the CU patterns were presented analogous to Simon et al. [18] and Hoch et al. [26] in a 3 -point scale (never, sometimes, and mostly). In the category 'usual times of day' of CU the items were: 'upon rising', 'at midday', 'in the evening', 'before going to sleep at night' and 'when waking up at night'. The category usual social context of CU was specified as: CU with 'friends', 'acquaintances', 'strangers' and 'alone'. In category usual method of CU the items were: 'smoking joint', 'smoking pipe', 'smoking water pipe', 'smoking a pail' and 'oral: tea or cookies'.

Gender Differences in the Patterns of Cannabis Use

\section{Participants}

During the 4 months of presenting the internet survey, 5,574 datasets were collected. After excluding the datasets of non-students, underaged participants ( $<18$ years of age) or missing data on age, gender or CU in last 12 months, 3,904 cases remained in the final dataset. There were $54.2 \%$ male participants. CU at all, ever, was reported by $59.6 \%$ of the female and $72.8 \%$ of the male participants. Current CU (at least once a month during last 12 months) was reported by 13.9 of all female and $28.2 \%$ of all male participants. Table 1 shows the gender-related demographic data and DSM-IV cannabis dependence as well as other substances use among the analysis sample: current cannabis users (CU at least once a month during the last 12 months). 
Table 2. Gender differences in frequencies of CU patterns among cannabis-using students (at least once a month during the last 12 months), $\mathrm{n}=843$

\begin{tabular}{|c|c|c|c|}
\hline CU pattern & $\begin{array}{l}\text { Females, \% } \\
(\mathrm{n}=248)\end{array}$ & $\begin{array}{l}\text { Males, \% } \\
(n=595)\end{array}$ & $\begin{array}{l}\chi^{2} \text { test } \\
\text { p value }\end{array}$ \\
\hline Frequency of CU $(n=843)$ & & & 0.231 \\
\hline $1-3$ days/month & 43.6 & 37.7 & \\
\hline 1-2 days/week & 21.0 & 25.4 & \\
\hline 3-4 days/week & 18.2 & 16.3 & \\
\hline Daily/almost daily & 17.3 & 20.7 & \\
\hline \multicolumn{4}{|l|}{ Usual time of day of $C U$} \\
\hline Upon rising $(\mathrm{n}=761)$ & & & 0.675 \\
\hline Never & 79.2 & 76.9 & \\
\hline Sometimes & 19.4 & 20.9 & \\
\hline Mostly & 1.4 & 2.2 & \\
\hline At midday $(\mathrm{n}=761)$ & & & 0.302 \\
\hline Never & 48.9 & 43.2 & \\
\hline Sometimes & 46.5 & 52.8 & \\
\hline Mostly & 4.6 & 4.0 & \\
\hline \multicolumn{3}{|c|}{ Before going to sleep at night $(\mathrm{n}=758)$} & 0.011 \\
\hline Never & 13.6 & 18.0 & \\
\hline Sometimes & 39.1 & 46.3 & \\
\hline Mostly & 47.3 & 35.7 & \\
\hline \multicolumn{3}{|c|}{ When waking up at night $(\mathrm{n}=743)$} & 0.037 \\
\hline Never & 84.8 & 91.0 & \\
\hline Sometimes & 10.9 & 7.1 & \\
\hline Mostly & 4.3 & 1.9 & \\
\hline \multicolumn{4}{|l|}{ People I use cannabis with } \\
\hline Friends $(\mathrm{n}=777)$ & & & 0.024 \\
\hline Never & 1.3 & 0.5 & \\
\hline Sometimes & 21.4 & 14.3 & \\
\hline Mostly & 77.2 & 85.2 & \\
\hline Strangers $(n=739)$ & & & 0.014 \\
\hline Never & 52.8 & 41.3 & \\
\hline Sometimes & 45.4 & 57.2 & \\
\hline Mostly & 1.9 & 1.5 & \\
\hline Alone $(\mathrm{n}=820)$ & & & 0.022 \\
\hline Never & 32.4 & 22.9 & \\
\hline Sometimes & 47.0 & 55.0 & \\
\hline Mostly & 20.6 & 22.1 & \\
\hline \multicolumn{4}{|l|}{ Method of CU } \\
\hline \multicolumn{3}{|l|}{ Smoking a joint $(n=774)$} & 0.023 \\
\hline Never & 0.5 & 1.6 & \\
\hline Sometimes & 4.5 & 9.6 & \\
\hline Mostly & 95.1 & 88.8 & \\
\hline \multicolumn{3}{|c|}{ Smoking water pipe $(\mathrm{n}=750)$} & $<0.001$ \\
\hline Never & 65.4 & 50.0 & \\
\hline Sometimes & 28.0 & 35.1 & \\
\hline Mostly & 6.5 & 14.9 & \\
\hline \multicolumn{3}{|l|}{ Smoking a pail $(\mathrm{n}=731)$} & 0.190 \\
\hline Never & 89.6 & 85.2 & \\
\hline Sometimes & 9.9 & 14.6 & \\
\hline Mostly & 0.5 & 0.2 & \\
\hline
\end{tabular}

For the age of the participants at the time of first CU, quite similar data in female and male current cannabis users were reported (females; mean $=16.6, \mathrm{SD}=2.34$; males: mean $=16.6$, $\mathrm{SD}=2.24$ ). Regular alcohol consumption (at least 3 times a week) was reported by $9.8 \%$ of all female and $16.8 \%$ of all male participants (19.0\% of female and $25.2 \%$ of male current cannabis users). The use of amphetamine or methamphetamine in the last 12 months was reported by $2.9 \%$ of all female and $5.1 \%$ of all male participants (15.0\% of female and $14.1 \%$ of male current cannabis users).

Data Analysis

The analyses of the gender differences in the patterns of CU and in their association with cannabis dependence were conducted in the subset of 843 participants who currently used cannabis (CU at least once a month during the last 12 months). In a first step, to identify gender-specific patterns of CU, gender differences in prevalence of $\mathrm{CU}$ patterns were calculated and tested using the $\chi^{2}$ test of independence. The results are shown in table 2 which includes only CU patterns with a significant association with DSM-IV cannabis dependence in either females or males. These were selected by regressing DSM-IV cannabis dependence in logistic regression separately on the CU patterns and testing their total explanatory value using the global Wald test. Other variables of CU patterns were regarded irrelevant for the transition from $\mathrm{CU}$ to cannabis dependence. Omitted variables were CU with 'acquaintances', CU 'in the evenings' CU via 'smoking pipe' and 'oral: tea or cookies' (results available on request).

Then, for the identified CU variables, again logistic regressions were fitted to determine the associations of patterns of $\mathrm{CU}$ with dependence separately for females and males. Associations were quantified with odds ratios while controlling for age (table 3). Differences in associations between females and males were tested in additional models which included the main effects of gender and $\mathrm{CU}$ pattern as well as their interaction terms gender ${ }^{*} \mathrm{CU}$ pattern. If the global Wald test was significant for the interaction terms in the model, it was assumed that the association varies over gender. Finally, for females and males separately, a multiple model was determined. Multiple models are shown in table 4 . Hereby, all variables significantly associated with cannabis dependence in the separate models above (assessed using the global Wald test) were jointly included into the respective multiple logistic regression while forcing the covariate age into the model. Variables that were then not significant anymore were stepwise deleted. The area under receiver operator characteristic curve (AUC) was calculated to assess the predictive value of each model. AUC values indicate the probability that a randomly chosen case with cannabis dependence scored higher in the modelbased probability for cannabis dependence (and varies from 0.5 to 1.0). All analyses were conducted by using STATA (version 10.0). Statistical significance was evaluated at a level of $\mathrm{p}=0.05$.

\section{Results}

Table 2 presents the prevalence of CU patterns in females and males currently using cannabis. Shown are the results of 11 out of $15 \mathrm{CU}$ patterns with a significant as- 
Table 3. Association of CU patterns with DSM-IV cannabis dependence (last 12 months) in female $(\mathrm{n}=248)$ and male $(\mathrm{n}=595)$ current cannabis-using students (at least once a month during the last 12 months), $\mathrm{n}=843$

\begin{tabular}{|c|c|c|c|c|c|c|c|c|c|c|}
\hline \multirow[t]{2}{*}{ CU patterns } & \multicolumn{5}{|c|}{ Females } & \multicolumn{5}{|c|}{ Males } \\
\hline & $\%$ & OR & $\mathrm{p}$ & gl-p & AUC & $\%$ & OR & $\mathrm{p}$ & gl-p & AUC \\
\hline Frequency of CU $(n=782)$ & & & & $<0.001$ & 0.69 & & & & $<0.001$ & 0.71 \\
\hline 1-3 days/month & 13.9 & 1 & & & & 19.9 & 1 & & & \\
\hline 1-2 days/week & 22.7 & 1.77 & 0.219 & & & 22.7 & 1.19 & 0.522 & & \\
\hline 3-4 days/week & 36.6 & 3.77 & 0.003 & & & 44.4 & 3.25 & $<0.001$ & & \\
\hline Almost daily/daily & 47.4 & 5.68 & $<0.001$ & & & 64.7 & 7.36 & $<0.001$ & & \\
\hline \multicolumn{11}{|l|}{ Usual time of day of $C U$} \\
\hline Upon rising $(\mathrm{n}=761)$ & & & & $<0.001$ & 0.74 & & & & $<0.001$ & 0.66 \\
\hline Never & 15.8 & 1 & & & & 25.8 & 1 & & & \\
\hline Sometimes & 61.9 & 8.51 & $<0.001$ & & & 59.7 & 4.28 & $<0.001$ & & \\
\hline Mostly & 66.7 & 11.8 & 0.048 & & & 75.0 & 9.30 & 0.001 & & \\
\hline At midday $(\mathrm{n}=761)$ & & & & $<0.001$ & 0.70 & & & & $<0.001$ & 0.66 \\
\hline Never & 14.2 & 1 & & & & 20.0 & 1 & & & \\
\hline Sometimes & 32.7 & 2.93 & 0.003 & & & 43.2 & 3.05 & $<0.001$ & & \\
\hline Mostly & 70.0 & 14.9 & $<0.001$ & & & 68.2 & 8.93 & $<0.001$ & & \\
\hline \multicolumn{3}{|c|}{ Before going to sleep at night $(\mathrm{n}=758)$} & & 0.002 & 0.65 & & & & $<0.001$ & 0.64 \\
\hline Never & 13.3 & 1 & & & & 17.5 & 1 & & & \\
\hline Sometimes & 18.6 & 1.50 & 0.512 & & & 30.1 & 1.98 & 0.023 & & \\
\hline Mostly & 35.6 & 3.96 & 0.020 & & & 47.4 & 4.19 & $<0.001$ & & \\
\hline When waking up at night $(\mathrm{n}=743)$ & & & & $<0.001$ & 0.65 & & & & $<0.001$ & 0.61 \\
\hline Never & 19.0 & 1 & & & & 30.0 & 1 & & & \\
\hline Sometimes & 47.8 & 4.25 & 0.002 & & & 76.3 & 7.70 & $<0.001$ & & \\
\hline Mostly & 77.8 & 13.7 & 0.002 & & & 90.0 & 21.9 & 0.004 & & \\
\hline \multicolumn{11}{|l|}{ People I use cannabis with } \\
\hline Friends $(\mathrm{n}=777)$ & & & & 0.171 & 0.57 & & & & $<0.001$ & 0.56 \\
\hline Never & 0 & - & & & & 33.3 & 1.18 & 0.895 & & \\
\hline Sometimes & 35.4 & 1.66 & 0.161 & & & 57.0 & 3.13 & $<0.001$ & & \\
\hline Mostly & 23.1 & 1 & & & & 29.7 & 1 & & & \\
\hline Strangers $(n=739)$ & & & & $<0.001$ & 0.68 & & & & 0.040 & 0.56 \\
\hline Never & 14.0 & 1 & & & & 28.2 & 1 & & & \\
\hline Sometimes & 39.8 & 4.30 & $<0.001$ & & & 37.8 & 1.56 & 0.022 & & \\
\hline Mostly & 25.0 & 1.90 & 0.591 & & & 25.0 & 0.86 & 0.856 & & \\
\hline Alone $(\mathrm{n}=820)$ & & & & $<0.001$ & 0.76 & & & & $<0.001$ & 0.67 \\
\hline Never & 7.0 & 1 & & & & 16.0 & 1 & & & \\
\hline Sometimes & 23.3 & 4.08 & 0.007 & & & 31.6 & 2.43 & 0.001 & & \\
\hline Mostly & 55.6 & 18.2 & $<0.001$ & & & 57.9 & 7.19 & $<0.001$ & & \\
\hline \multicolumn{11}{|l|}{ Method of CU } \\
\hline Smoking a joint $(\mathrm{n}=774)$ & & & & 0.137 & 0.57 & & & & 0.012 & 0.55 \\
\hline Never & 0.0 & - & & & & 22.2 & 0.60 & 0.528 & & \\
\hline Sometimes & 50.0 & 3.04 & 0.095 & & & 52.8 & 2.42 & 0.003 & & \\
\hline Mostly & 24.5 & 1 & & & & 31.7 & 1 & & & \\
\hline Smoking water pipe $(\mathrm{n}=750)$ & & & & 0.095 & 0.59 & & & & $<0.001$ & 0.61 \\
\hline Never & 22.1 & 1 & & & & 27.2 & 1 & & & \\
\hline Sometimes & 23.3 & 1.07 & 0.859 & & & 35.1 & 1.47 & 0.065 & & \\
\hline Mostly & 57.1 & 4.84 & 0.008 & & & 55.0 & 3.34 & $<0.001$ & & \\
\hline Smoking a pail $(\mathrm{n}=731)$ & & & & 0.166 & 0.58 & & & & 0.032 & 0.55 \\
\hline Never & 22.6 & 1 & & & & 31.7 & 1 & & & \\
\hline Sometimes & 38.1 & 2.08 & 0.132 & & & 43.2 & 1.68 & 0.041 & & \\
\hline Mostly & - & - & & & & - & - & & & \\
\hline
\end{tabular}


Table 4. Association of CU patterns with DSM-IV cannabis dependence (last 12 months), multiple logistic regressions in female and male cannabis-using students (at least once a month during the last 12 months), controlled for age

\begin{tabular}{|c|c|c|c|c|}
\hline Characteristic & OR & $95 \% \mathrm{CI}$ & $\mathrm{p}$ value & AUC \\
\hline \multicolumn{5}{|l|}{ Female $(\mathrm{n}=192)$} \\
\hline Usual time of day of use: upon rising (never vs. sometimes) & 5.71 & $2.18,14.95$ & $<0.001$ & \\
\hline Usual time of day of use: when waking up at night (never vs. mostly) & 7.24 & $1.00,52.35$ & 0.050 & \\
\hline \multirow[t]{2}{*}{ People I use cannabis with: alone (never vs. mostly) } & 9.67 & $2.08,44.87$ & 0.004 & \\
\hline & & & & 0.86 \\
\hline \multicolumn{5}{|l|}{ Male $(\mathrm{n}=492)$} \\
\hline Frequency of use (1-3 days/month vs. 3-4 days/week) & 1.97 & $1.03,3.77$ & 0.042 & \\
\hline Frequency of use (1-3 days/month vs. daily/almost daily) & 3.58 & $1.87,6.87$ & $<0.001$ & \\
\hline Usual time of day of use: upon rising (never vs. sometimes) & 1.72 & $1.00,9.97$ & 0.049 & \\
\hline Usual time of day of use: before going to sleep at night (never vs. sometimes) & 3.86 & $1.52,9.76$ & 0.004 & \\
\hline Usual time of day of use: before going to night sleep (never vs. mostly) & 22.9 & $1.33,395.2$ & 0.031 & \\
\hline \multirow[t]{2}{*}{ People I use cannabis with: alone (never vs. mostly) } & 2.64 & $1.22,5.72$ & 0.014 & \\
\hline & & & & 0.77 \\
\hline
\end{tabular}

sociation with DSM-IV cannabis dependence in either females or males.

The male cannabis users more frequently reported CU via a 'water pipe', with 'friends', with 'strangers' and 'alone' compared to female users. The female cannabis users more frequently reported CU by smoking a 'joint', 'before going to sleep at night' and 'when waking up at night'. For the items 'frequency' of CU, CU 'upon rising' and 'at midday', there was no evidence of any gender differences in prevalence.

Table 3 presents the gender-specific associations of the CU patterns with DSM-IV cannabis dependence.

Most of the variables of the CU patterns were associated with the presence of DSM-IV cannabis dependence in both genders. In female and male cannabis users 'frequency' of CU, CU 'upon rising', 'at midday' and 'alone' had the strongest association with cannabis dependence. As evidenced by the significant interaction term 'CU with strangers* ${ }^{*}$ gender' (odds ratio 0.38; 95\% confidence interval $0.18,0.82$; p value 0.013 ), item CU 'with strangers' showed a stronger association with DSM-IV cannabis dependence in female compared to male cannabis users. CU with 'friends', via 'smoking a joint', smoking 'water pipe' and 'smoking a pail' were associated with DSM-IV cannabis dependence in a global test in males only by reason of limitations on statistical power in analysis for females.

Table 4 presents the multiple models for male and female cannabis users. In female cannabis users, CU 'upon rising', 'when waking up at night' and 'alone' remained significant in the multiple model. In male cannabis users the remaining variables were 'frequency' of $\mathrm{CU}, \mathrm{CU}$ 'upon rising, 'before going to sleep at night' and 'alone'.

\section{Discussion}

The present findings indicate that female current cannabis users show considerably different patterns of $\mathrm{CU}$ compared to males. Nevertheless there are gender similarities but also slight gender differences in the association of the patterns of CU with DSM-IV cannabis dependence and slightly different multiple models predicting the presence of DSM-IV cannabis in females and males.

The excessive CU method of the water pipe is more common for male rather than female cannabis users. Compared to females, males seem to have more of an affinity for excessive use methods, in order to consume a large amount of cannabis fast. Also, males seem to have more of an affinity toward 'getting high'. CU in a context with strangers is also more common in male cannabis users compared to female cannabis users. This seems to indicate that males more often consume cannabis in public situations such as parties and that they have fewer inhibitions using cannabis in front of strangers. On the other hand, males reported a higher prevalence of $\mathrm{CU}$ in all other social context items compared to females, including CU 'with friends' and 'alone' what makes it difficult to 
conclude to gender differences in social context of CU. Female cannabis users show a higher $\mathrm{CU}$ prevalence in relation to get to sleep (CU 'before going to sleep at night' and 'when waking up at night'). Chabrol et al. [10] reported that $\mathrm{CU}$ is more important to females in coping with tension and stressors. These stressors may cause more sleep disturbance in female cannabis users compared to males or females might be more willing to use cannabis for coping. Otherwise, results may stay in line with Budney et al. [19], which named sleep problems as an important withdrawal symptom in cannabis addicts, and the findings by Grant et al. [12] showing a higher endorsement of withdrawal in women. In a line with this, the current results show 'use because of withdrawal' as the only DSM-IV criteria with higher prevalence in females compared to males. On the other hand, there might be a different functioning, interpretation or endorsing of some criteria for cannabis-related disorders, reported by Agrawal and Lynskey [9]. However, the results in general link to gender differences in the functionality and, thus, in the progression from onset of use to regular use and cannabis dependence. This supports the findings by Chabrol et al. [10], which found a different functionality of CU in female compared to male French students and that $\mathrm{CU}$ might be more important in females as coping strategy while males more frequently report mood enhancement as their main motive for CU.

Observing gender differences in the association of $\mathrm{CU}$ patterns with DSM-IV cannabis dependence the present study yielded the following findings: in most CU patterns there is a similar association with DSM-IV cannabis dependence of females compared to males. Considerable gender differences were found in CU 'with strangers' only. In females, CU 'with strangers' is much more related to DSM-IV cannabis dependence than in males. This item shows a remarkable association with the presence of dependence in females only. However, this item declares no additional variance of the presence of dependence in females. Furthermore, the results from both genders confirm the often reported role of CU 'frequency' as strongly associated with DSM-IV cannabis dependence [e.g. 8, 13, 14, 16]. For CU at an early time of day and 'alone', a similarly high association with DSM-IV cannabis dependence compared to CU 'frequency' [13] exists for both genders. In male and female cannabis users the predictive value of a multiple model is higher than 'frequency' of CU or any other item alone. This means that further items beside 'frequency' of CU, especially CU on early times of day and CU 'alone' explain additional variance of the presence of dependence. In females and males, combined data of several items of the CU patterns seem to allow for the identification of cannabis users with DSM-IV cannabis dependence on a strong level, while variable 'age' does not explain additional variance. This shows how valuable it is to ask about the CU patterns in order to detect high-risk cannabis users in clinical practice - especially CU 'on early times of day' and 'alone' - in both genders. For the clinician, CU patterns should be easy enough to recognize and to verify. For this, it might be useful create a standardized test. However, gender differences appear too small for consideration.

The results allow for additional conclusions: there is an association of regular $\mathrm{CU}$ via excessive method water pipe and cannabis dependence in both genders, although CU via water pipe explains no additional variance of the presence of dependence to other CU patterns. It remains unclear whether excessive use methods cause DSM-IV cannabis dependence or are symptoms of. However, results show the importance of investigating the role of excessive use methods in the development of cannabis dependence. In contrast to other illegal substances, e.g. heroin [e.g. 27], for CU little is known about it. Furthermore, as additional conclusions, results go along with further studies that use of illicit substances and current heavy alcohol consumption are associated with $\mathrm{CU}$ and cannabis dependence $[14,28,29]$.

The present results should, however, be interpreted within the methodological limitations of the present study. Using an internet survey, a selection bias must be anticipated due to the different access options to the internet. Moreover, the possibility that some participants completed the survey more than once cannot be excluded as no personal identification data were collected. The target population presents another issue. Since the study focused on university students, the results cannot be generalized for subjects that have a lower educational level or are in a different age range. It remains unclear whether the results would be applicable to cannabis user populations other than students. It might be assumed that the gender differences in the CU patterns vary between different educational classes. Cultural influences also remain unknown too. Furthermore, it remains unclear whether other items for $\mathrm{CU}$ patterns might be more suitable for expressing the aims of the study. Moreover, the diagnosis of cannabis abuse and cannabis dependence was based on self-reports and was not verified by an experienced clinician. Finally, the data were derived from a cross-sectional design and therefore do not allow for a causal interpretation of whether the CU patterns are the symptoms of DSM-IV cannabis dependence or, in fact, 
the cause of it. Future studies using a longitudinal design will be needed to test this hypothesis.

In conclusion, the results support the thesis about the different functionality of $\mathrm{CU}$ in females compared to males. Apparently, use patterns have a similar association with cannabis dependence in females as well as in males. Exploring more CU patterns in addition to 'frequency' of $\mathrm{CU}$, especially CU on early times of day and apart of social contexts, appears to be rather appropriate for diagnostic approaches to both genders. The examination of
CU could, thus, contribute considerably to a better detection of high-risk subjects and to early therapeutic interventions in both female and male cannabis users.

\section{Acknowledgements}

We would like to thank Robert Gründler, Astrid Becker and Roland Schulz for providing the internet survey. Furthermore, our appreciation goes to all the students participating in the survey for their willingness to be included in the present study.

\section{References}

1 European Monitoring Centre for Drugs and Drug Addiction (EMCDDA): Annual Report 2009. Lisbon, European Monitoring Centre for Drugs and Drug Addiction, 2009.

2 Hall W, Pacula RL: Cannabis Use and Dependence. Port Melbourne, Cambridge University Press, 2003.

3 Petersen KU, Thomasius R: Auswirkungen von Cannabiskonsum und -missbrauch: Eine Expertise zu gesundheitlichen und psychosozialen Folgen. Ein systematisches Review der international publizierten Studien von 1996-2006. Lengerich, Pabst Science Publishers, 2007.

4 Agosti V, Nunes E, Levin F: Rates of psychiatric comorbidity among US residents with lifetime cannabis dependence. Am J Drug Alcohol Abuse 2002;28:643-652.

5 Buckner JD, Mallot MA, Schmidt NB, Taylor J: Peer influence and gender differences in problematic cannabis use among individuals with social anxiety. J Anxiety Disord 2006; 20:1087-1102.

6 Kraus L, Pfeiffer-Gerschel T, Pabst A: Cannabis und andere illegale Drogen: Prävalenz, Konsummuster und Trends. Ergebnisse des Epidemiologischen Suchtsurveys 2006. Sucht 2008;54:16-25.

7 Pfeiffer-Gerschel T, Kipke I, Flöter S, Lieb C, Raiser P: Bericht 2009 des nationalen REITOX-Knotenpunkts Deutschland an die EDBB. Neue Entwicklungen, Trends und Hintergrundinformationen zu Schwerpunktthemen. München, Institut für Therapieforschung, 2009.

8 Coffey C, Carlin JB, Lynskey M, Li N, Patton GC: Adolescent precursors of cannabis dependence: findings from the Victorian Adolescent Health Cohort Study. Br J Psychiatry 2003;182:330-336.

9 Agrawal A, Lynskey MT: Does gender contribute to heterogeneity in criteria for cannabis abuse and dependence? Results from the National Epidemiological Survey on Alcohol and Related Conditions. Drug Alcohol Depend 2007;88:300-307.

10 Chabrol H, Ducongé E, Casas C, Roura C, Carey KB: Relations between cannabis use and dependence, motives for cannabis use and anxious, depressive and borderline symptomatology. Addict Behav 2005;30:829-840.

11 Poulin C, Hand D, Boudreau B, Santor D: Gender differences in the association between substance use and elevated depressive symptoms in a general adolescent population. Addiction 2005;100:525-535.

12 Grant JD, Scherrer JF, Neumann RJ, Todorov AA, Price RK, Buchholz KK: A comparison of the latent class structure of cannabis problems among adult men and women who have used cannabis repeatedly. Addiction 2006 101:1133-1142.

13 Noack R, Höfler M, Gründler R, Becker A Schulz R, Paul K: Konsummuster als Kovariablen von DSM-IV Cannabisabhängigkeit. Sucht 2009;55:137-147.

14 Sydow K, Lieb R, Pfister H, Höfler M Wittchen HU: What predicts incident use of cannabis and progression to abuse and dependence? A 4-year prospective examination of risk factors in a community sample of adolescents and young adults. Drug Alcohol Depend 2002;68:49-64.

15 Li TK, Hewitt BG, Grant BF: The alcohol dependence syndrome, 30 years later: a commentary - the 2006 H. David Archibald Lecture. Addiction 2007;102:1522-1530.

16 Chen K, Kandel DB, Davies M: Relationship between frequency and quantity of marijuana use and last year proxy dependence among adolescence and adults in the United States. Drug Alcohol Depend 1997;46:5367.

17 European Monitoring Centre for Drugs and Drug Addiction (EMCDDA): Annual Report 2007. Lisbon, European Monitoring Centre for Drugs and Drug Addiction, 2007.

18 Simon R, Sonntag D, Bühringer G, Kraus L: Cannabisbezogene Störungen: Umfang, Behandlungsbedarf und Behandlungsangebot in Deutschland. Munich, Institut für Therapieforschung, 2004

19 Budney AJ, Hughes JR, Moore BA, Vandrey R: Review of the validity and significance of cannabis withdrawal syndrome. Am J Psychiatry 2004; 161:1967-1977.
20 Hesse M, Tutenges S, Schliewe S: The use of tobacco and cannabis at an international music festival. Eur Addict Res 2010;16:208212.

21 Beck KH, Caldera KM, Vincent KB, O'Grady KE, Wish ED, Arria AM: The social context of cannabis use: relationship to cannabis use disorders and depressive symptoms among college students. Addict Behav 2009;34:764768 .

22 Bonnet U, Harries-Heder K, Leweke FM, Schneider U, Tossmann P: AWMF-Leitlinie: Cannabisbezogene Störungen. Fortschr Neurol Psychiatr 2004;72:318-329.

23 American Psychological Association: Ethical principles of psychologists and code of conduct. Am Psychol 2002;57:1060-1073.

24 Keller HE, Lee S: Ethical issues surrounding human participants research using the internet. Ethics Behav 2003;13:211-219.

25 Wittchen HU, Pfister H: DIA-X-Interviews: Manual für Screeningverfahren und Interview; Interviewheft Längsschnittuntersuchung (DIA-X-Lifetime); Ergänzungsheft (DIA-X Lifetime); Interviewheft Querschnittuntersuchung (DIA-X 12 Monate), Ergänzungsheft (DIA-X 12 Monate); PCProgramm zur Durchführung des Interviews; Auswertungsprogramm. Frankfurt am Main, Swets \& Zeitlinger, 1997.

26 Hoch E, Noack R, Rohrbacher H, Pixa A, Henker J, Bühringer G, Wittchen HU: Gezielte Behandlung von Cannabisstörungen - das modulare, kognitiv-behaviorale Entwöhnungsprogramm 'CANDIS'. Sucht Aktuell 2007;2:57-59.

27 Hadland SE, Kerr T, Marshall BDL, Small W, Lai C, Montaner JS, Wood E: Non-injection drug use patterns and history of injection among street youth. Eur Addict Res 2010;16: 91-98.

28 Hakkarainen P, Metso L: Joint use of drugs and alcohol. Eur Addict Res 2009;15:113-120.

29 Chen CY, O'Brien MS, Anthony JC: Who becomes cannabis dependent soon after onset of use? Epidemiological evidence from the United States: 2000-2001. Drug Alcohol Depend 2005;79:11-22. 